\title{
O REFORÇO AOS ESTIGMAS DE GÊNERO: MENINAS NO SISTEMA SOCIOEDUCATIVO BRASILEIRO
} THE REINFORCEMENT OF GENDER STIGMAS: GIRLS IN THE BRAZILIAN CORRECTIONAL SYSTEM

\author{
Douglas Norkevicius ${ }^{1}$ \\ FGV -SP
}

\section{Resumo}

O presente artigo observou a presença dos marcadores típicos da diferença de gênero que se apresentam em casos específicos do funcionamento da justiça juvenil. Através da identificação de figuras de gênero que são incentivadas na execução de medidas socioeducativas de internação, este trabalho analisou a localização das mesmas figuras em fases anteriores do processo de criminalização: o ato delitivo e sua relação com as sentenças que impõem as medidas às meninas que atravessam o sistema socioeducativo brasileiro. Dessa forma, buscou apresentar a relação paradoxal entre a penalização dessas figuras e sua imposição, quando na execução das medidas socioeducativas.

Palavras-Chave

Gênero. Criminalização Secundária. Justiça Juvenil. Execução de Medidas Socioeducativas.

\section{Abstract}

This article studied the presence of typical gender differentiation markers that present themselves in specific cases of the functioning of juvenile justice. Through the identification of gender figures that are encouraged in the execution of socioeducational measures of detention, this work analyzed the presence of the same

${ }^{1}$ Estudante de graduação na FDUSP. Assistente acadêmico na FGV Direito SP. 
figures in previous stages of the criminalization process: the criminal act and its relationship with the sentences that impose the measures on girls that go through the Brazilian socio-educational system. Thus, it sought to present the paradoxical relationship between the penalization of such figures and their imposition, when carrying out socio-educational measures.

\section{Keywords}

Gender. Secondary Criminalization. Juvenile Justice. Execution of Correctional Measures.

\section{INTRODUÇÃO: PROTEÇÃO INTEGRAL AS MENINAS FORA DA LEI?}

As dissimulações de gênero atravessam as gerações e atingem indivíduos de todas as idades, ${ }^{2}$ como elaboram DINIZ, PISCITELLI, COPELLO e tantas outras professoras. Nesse sentido, é importante observar como estes impactos, por vezes negativos, acabam por se materializarem nas diferentes fases da vida de uma pessoa humana. Essa notoriedade ganha relevância se tomada sobre fundamento de que as fases chamadas de infância e juventude, no Brasil, dispõem de proteção integral ${ }^{3}$ e que a

${ }^{2}$ Cf. PISCITELLI, A. Recriando a (categoria) mulher? In: ALGRANTI, L. (Org.). A prática feminista e o conceito de gênero. Textos Didáticos, n. 48. Campinas: IFCH/Unicamp, 2002, p. 7.

${ }^{3}$ LIMA, F. S; VERONESE, J. R. P. Direitos da criança e do adolescente. A necessária efetivação dos direitos fundamentais. Coleção pensando o direito no século XXI. Vol. V. Florianópolis: FUNJAB, 2012, p. 51. 
responsabilidade sobre tal proteção é compartilhada entre o Estado e seus agentes oficiais, a sociedade e as famílias. ${ }^{4}$

Este campo bastante ampliado de proteção ainda não foi concretizado integralmente em nossa cultura jurídica, ${ }^{5}$ mesmo passados trinta anos desde a promulgação do Estatuto da Criança e do Adolescente. Vale destacar que as legislações passadas que trabalhavam o tema mais serviam para culpabilizar crianças, adolescentes e famílias empobrecidas. ${ }^{6}$ A exemplo desses modelos doutrinários antigos, pode-se citar os Códigos de Menores de 1927 e de 1979, inseridos na chamada etapa tutelar, que buscavam, baseados nas teorias preventivas especiais positivas - as teorias de reabilitação - resgatar as crianças e adolescentes da criminalidade, do abandono e da pobreza. ${ }^{7} \mathrm{~A}$ efetivação das garantias e direitos destinados à essa população ainda depende do esforço e articulação de setores diversificados da sociedade.

No Brasil, as disposições são bastante modernas, como explicita a doutrina da proteção integral, que pode ser encontrada no artigo 227 da Constituição Federal de 1888. Foi incorporada para contemplar uma nova forma de proteção destes indivíduos: a de responsabilidade compartilhada, como citado acima. Tal
${ }^{4}$ Ibid., p. 53.
${ }^{5}$ Ibid., p. 53 ss.
${ }^{6}$ Ibid., p. 54.
${ }^{7}$ Ibid., p. 57. 
determinação tinha como objetivo a ampliação do campo de proteção das normas voltadas à comunidade brasileira de crianças e adolescentes, vez que os responsáveis pela efetivação destes direitos estariam localizados não só no Estado, mas também em toda a sociedade e nos seios familiares. ${ }^{8}$ Dessa forma pretende garantir que a proteção destes direitos se dará com absoluta prioridade, como dispõe o próprio artigo 227 da Constituição e também os artigos iniciais do Estatuto da Criança e do Adolescente.

Entretanto, mesmo dispondo de diplomas tão modernos, uma realidade dura se impõe quando o assunto é Justiça Juvenil. Está estabelecido um sistema materialmente antagônico ao elaborado pela legislação como o ECA (Estatuto da Criança e do Adolescente) e a Lei do SINASE, incapaz de realizar qualquer objetivo ressocializante e tampouco reeducativo, servindo apenas como instrumento de violação massiva de direitos e garantias estabelecidos pela lógica da infância e juventude apresentada na legislação. ${ }^{9}$

Essa lógica de punição de adolescentes revela uma incapacidade do judiciário de enfrentar a questão da delinquência

${ }^{8}$ LIMA, F. S; VERONESE, J. R. P., op. cit., p. 57.

${ }^{9}$ SOUZA, F. S. V.; FERRAZ, H. G. A responsabilidade do judiciário brasileiro no encarceramento em massa juvenil: um estudo de caso do HC 346.380-SP, STJ. Revista Brasileira de Ciências Criminais. vol. 129. ano 25. p. 259. São Paulo: Ed. RT, março 2017. 
juvenil, já que tais trajetórias tendem a serem intensificadas justamente nos primeiros anos da juventude, como apresenta Le Blanc, da Faculdade de Criminologia da Universidade do Canadá: ${ }^{10}$

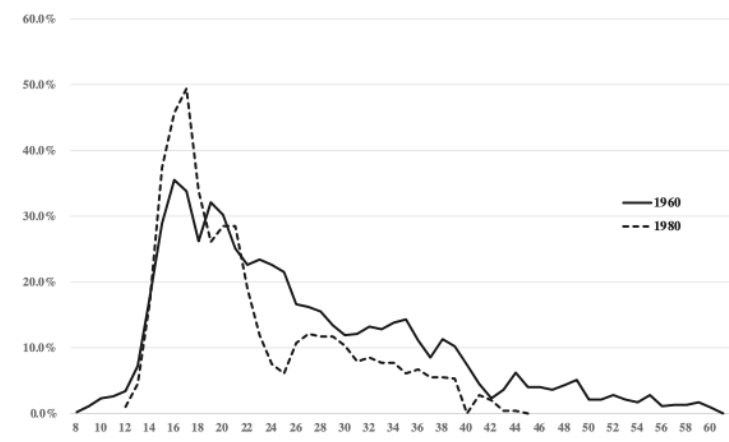

FIGURE 1 The age-crime cunve of the birth cohorts of 1960 and 1980, yearly percentage of active males

Gráfico retirado do estudo On the future of the individual longitudinal age-crime curve. ${ }^{11}$

10 Neste ponto, é importante realizar a separação dos estudos criminológicos desenvolvimentistas dos estudos criminológicos críticos, ambos presentes na articulação de ideias deste artigo. Os primeiros são voltados à concretização do fenômeno da delinquência em âmbito individual e subjetivo, enquanto os segundos pretendem identificar as estruturas formais e informais de poder que compõem a malha de agentes criminalizadores e de controle.

${ }^{11}$ LE BLAC, M. On the future of the individual longitudinal age-crime curve. Crim Behav Ment Health. vol. 30. 2020. p. 183-195. Disponível em https://doi.org/10.1002/cbm.2159. 
É possível afirmar, observando os dados acima, que é, justamente, nas fases componentes da adolescência que devem ser garantidos todos os direitos de um indivíduo, em busca do distanciamento deste dos sistemas formais de controle destinados à adolescentes em conflito com a lei ou dos sistemas penais em seu sentido amplo.

Nesse cenário, o gênero, enquanto imposição de figuras e formas de hierarquia ${ }^{12}$, desempenha uma grande influência sobre as adolescentes, se imiscuindo às formas de criminalização $^{13}$ e, diversas vezes, determinando àquela adolescente criminalizada perante os agentes do sistema de controle. Essa relação direta entre o formato que as infrações são entendidas pelas varas de infância e juventude e as pressões do gênero pode ser inferida a partir dos estudos apresentados neste artigo.

Paradoxalmente, as mesmas estruturas invisíveis que foram capazes de vincular, para o Judiciário, àquela adolescente ao ato infracional são reforçadas ao longo do cumprimento das medidas socioeducativas de internação. É sob este ponto que este

${ }^{12}$ Cf. SAFFIOTI, H. I. B. Gênero, patriarcado, violência. 2. ed. São Paulo: Graphium, 2011.

${ }^{13}$ COPELLO, P. L. Mujeres em el abismo: delinquência feminina em contextos de violência o exclusión. Revista Electrónica de Ciência Penal y Criminologia, 21, 21, 2019, p. 2 ss. Disponível em http://criminet.ugr.es/recpc/. Último acesso em set. de 2020. 
artigo pretende se debruçar. $\mathrm{Na}$ primeira seção serão aproximados conceitos da delinquência feminina em contextos de violência e exclusão e como o gênero é um importante elemento para composição destes contextos. Em segundo plano, serão apresentados formatos aos quais a Justiça Juvenil implica as relações determinadas pelo gênero nas sentenças impostas a essas meninas. Posteriormente, serão apresentadas as formas de execução das medidas socioeducativas para garotas em conflito com a lei e como esses formatos de execução podem intensificar os contextos primeiros que estimularam a prática da infração. Para tal, foram estudados dois relatórios de pesquisa fundamentais no tocante ao tema: o relatório (i) Meninas fora da lei: medida socioeducativa de internação no Distrito Federal ${ }^{14} \mathrm{e}$ (ii) Dos espaços aos direitos: a realidade da ressocialização na aplicação das medidas socioeducativas de internação das adolescentes do sexo feminino em conflito com a lei nas cinco regiões. ${ }^{15}$

A situação da nossa população de adolescentes do sexo feminino cumprindo medidas socioeducativas de internação

${ }^{14}$ DINIZ, D. Meninas fora da lei: a medida socioeducativa de internação no Distrito Federal. Brasília: LetrasLivres, 2017.

${ }^{15}$ BRASIL. Dos espaços aos direitos. A realidade da ressocialização na aplicação das medidas socioeducativas de internação das adolescentes do sexo feminino em conflito com a lei nas cinco regiões. Coord. MELLO, M. M. P. Pesquisadores BASTOS, C. A. V, et al. Brasília: Conselho Nacional de Justiça, 2015. 
pode não apresentar números vultuosos, mas é dever do cidadão (legalmente) fazer com que essas meninas tenham seus direitos protegidos, como estabelece, expressamente, nossa moderna legislação vigente.

\section{GÊNERO E SUAS DISSIMULAÇÕES}

Os estudos de gênero e sexualidade, que vêm ganhando corpo no interior da comunidade acadêmica, denunciam, sobretudo, formatos de poder e hierarquia. ${ }^{16}$ Essa relação de poder, entretanto, é dinâmica e alcança diversos âmbitos formais e informais da sociedade. Essas disposições, que retratam as figuras hierárquicas marcadas sobretudo pelo gênero podem ser observadas, por exemplo, nas alterações recentes de leis civis e penais: novas construções de tipificações legais que buscavam salientar as violências de gênero ou desmantelar relações jurídicas baseadas nesta mesma violência. Podemos citar a Lei Maria da Pena, as alterações que tipificaram o feminicídio ou o assédio sexual, que geram, constantemente, um amplo debate nas ciências jurídicas.

As chamadas relações de gênero, baseadas nestas hierarquias, em geral, dependem, como qualquer formato de

${ }^{16}$ DINIZ, D.; GUMIERI, S. Violência de gênero no Brasil: ambiguidades da política criminal. In: GOMES, M. G. M.; FALAVIGNO, C. F.; MATA; J. [Orgs.]. Questões de gênero: uma abordagem sob a ótica das ciências criminais. Belo Horizonte: D’Plácido, 2018. p. 197. 
opressão, de violência para seu modelo de imposição. ${ }^{17}$ Assim, esta estrutura, apresentada como relação de gênero, é, necessariamente, violentogênica, ${ }^{18}$ vez que a materialização destas hierarquias depende do alcance da posição masculina de dominação em diversos formatos. A masculinidade, como atributo, deve ser reproduzida, portanto, em formato cíclico ${ }^{19} \mathrm{e}$ essa reprodução acaba por incorporada nos modelos oficiais de controle, geridos e administrados, em sua maioria, por indivíduos generificados como masculinos.

Tais incorporações podem, então, serem encontradas nos formatos dados aos delitos específicos imputados a indivíduos generificados como femininos. São cenários de criminalização primária e também secundária que dependem, fundamentalmente, das figuras de gênero para se darem, estabelecendo uma padronização da tratativa de delinquência feminina/criminalidade feminina ${ }^{20}$ por parte do Estado.

Esses atos/fatos, apresentados como criminalidade feminina, possuem, por compartilharem um eixo de tipificação,

${ }^{17}$ SAFFIOTI, 2011, passim.

${ }^{18}$ SEGATO, L. R. Feminicidio y femicidio: conceptualización y apropriación. In: JIMÉNEZ, P.; RONDEROZ, K (Ed.). Feminicidios: um fenómeno global de Lima a Madrid. Bruxelas: Heinrich Böll Stiftung, 2010. p. 5 ss.

${ }^{19}$ Ibid., p. 6.

${ }^{20}$ COPELLO, op. cit., p. 2 ss. 
circunstâncias muito parecidas de ocorrência, ${ }^{21}$ associadas ao quadro de violência experimentado por àquela mulher criminalizada e "razões de marginalidade econômica e social igualmente atravessadas por estereótipos de gênero". ${ }^{22}$

A professora Patricia Coppelo elaborou um estudo acerca da delinquência feminina, abordando o tema através da observação de certos padrões que se apresentavam nas ocasiões de crimes cometidos por indivíduos do gênero feminino. $O$ estudo buscou identificar quais razões do gênero eram observadas nos injustos cometidos e quais eram observáveis na condição anterior daquela mulher, muitas vezes em situações de vulnerabilidade social marcada pelos mesmos estereótipos. ${ }^{23}$ Selecionados os delitos que apresentavam situações de violência condicionadas pelas dissimulações de gênero, foram estes divididos em grupos de situações comuns, sendo eles (i) o grupo dos delitos de "status", marcadamente femininos, (ii) o grupo das situações nas quais de situações nas quais mulheres recorrem ao tráfico de drogas, muitas vezes associadas à situação econômica bastante vulnerável e pressionadas por encargos familiares.

O estudo acabou por identificar a confirmação de sua hipótese inicial: nos três grupos de situações estudadas foram

${ }^{21}$ COPELLO, op. cit., p. 36.

${ }^{22}$ COPELLO, op. cit., p. 3 ss.

${ }^{23}$ COPELLO, op. cit., p. 37. 
identificadas circunstâncias de vulnerabilidade e violência determinadas pelas relações de gênero. A lógica deste artigo tem, neste ponto, seu início: situações específicas impostas ao indivíduo generificado enquanto mulher podem ser um incremento de risco para sua criminalização pelos órgãos de controle oficiais, ou seja, o motivo de imposição de sua pena. No caso, específico de adolescentes do sexo feminino, o motivo de sua aproximação ao sistema socioeducativo.

\section{a. A JUSTIÇA JUVENIL COMO EQUIPAMENTO DE CRIMINALIZAÇÃO DE MENINAS}

Como elaboram Flora Sartorelli e Hamililton Gonçalves, em artigo citado recentemente pelo ministro Gilmar Mendes no HC 143988/ES, ${ }^{24}$ o sistema de Justiça Juvenil é um interessante agente do complexo fenômeno contemporâneo chamado de encarceramento em massa. ${ }^{25}$

24 BRASIL. Supremo Tribunal Federal (2. Turma). Habeas Corpus Coletivo 143988/ES. Habeas Corpus coletivo. Cumprimento de medidas socioeducativas de internação. Impetracão voltada a corrigir alegada superlotação em unidades [...]. Relator Min. Edson Fachin. 24 de agosto de 2020. Disponível em http://portal.stf.jus.br/processos/downloadPeca.asp?id=15344303832\&ext=.pdf.

Último acesso em setembro de 2020.

${ }^{25}$ SOUZA, F. S. V.; FERRAZ, H. G., op. cit., p. 259. 
Conforme colocado na introdução deste artigo, o processo de criminalização de adolescentes é diverso do processo de encarceramento da população adulta, por conta da modernidade dos diplomas que tratam do tema no Brasil mesmo a despeito das bastantes tentativas de recrudescimento destes dispositivos. Ainda assim, os autores demonstram que os vícios da formatação cultural em volta da pena como medida natural ao delito, ${ }^{26}$ que é um ideário bastante sólido na justiça criminal para adultos, acaba por integrar-se ao pensamento da aplicação das disposições legais que regem o sistema de crianças e adolescentes. Isso se dá, em partes, por conta do caráter aberto das normas dos dispositivos do complexo normativo que trata do tema, abrindo margem para arbitrariedades dos agentes operantes do direito ${ }^{27}$. Assim, a mesma lógica jurídica dominante no sistema criminal adulto, que enseja ao encarceramento em massa, acaba materializando-se na justiça juvenil brasileira. A legitimidade dessas condutas e decisões, apesar de seu conteúdo opressor e punitivista, é amparada nas concepções da etapa tutelar ou menorista - aquela na qual os menores infratores deveriam ser resgatados e protegidos da pobreza e da delinquência. ${ }^{28}$

${ }^{26}$ SOUZA, F. S. V.; FERRAZ, H. G., op. cit., p. 261.

${ }^{27}$ SOUZA, F. S. V.; FERRAZ, H. G., op. cit., p. 261 ss.

${ }^{28}$ Cf. SOUZA, F. S. V.; FERRAZ, H. G., op. cit., p. 262. Nesse mesmo sentido, LIMA, F. S; VERONESE, J. R. P., op. cit., p. 57. 
A lógica menorista pode ser evidenciada, por exemplo, quando do julgamento do HC 348.360-SP pelo STJ, como demonstram os autores, mesmo após o estabelecimento de novas normas que deveriam basear o funcionamento da Justiça Juvenil a partir de lógica diversa: a garantista. ${ }^{29}$ Dessa forma, é possível identificar a operacionalização de estruturas e ferramentas, muitas vezes, não enunciadas, invisíveis. Tal afirmação é indicada por três razões: ${ }^{30}$ (i) o ideário de que adolescentes são indivíduos/sujeitos moldáveis e, por isso, dependem de intervenções mais extensivas, mesmo que a prática delitiva cometida por aquele sujeito não indique um adolescente que necessite desse nível de intervenção; (ii) também é possível traduzir o ideário de que a institucionalização é capaz de promover a reintegração/ressocialização daquele indivíduo e; (iii) o caráter aberto das normas que regulam o sistema de Justiça Juvenil, abrindo campo para atuação desmedida dos operadores do sistema. ${ }^{31}$

Esse tripé que abre espaço para a intervenção mais discricionária dos operadores do direito também carregará as dissimulações primeiras expostas: as de gênero.

${ }^{29}$ SOUZA, F. S. V.; FERRAZ, H. G., op. cit., p. 276.

${ }^{30}$ SOUZA, F. S. V.; FERRAZ, H. G., op. cit., p. 277 ss.

${ }^{31}$ SOUZA, F. S. V.; FERRAZ, H. G., op. cit., p. 277. 
Um estudo publicado na Revista da Faculdade de Direito da Universidade Federal do Paraná (UFPR) ${ }^{32}$ analisou vinte e oito sentenças, proferidas por juízos da Infância e Juventude de Pernambuco, que impunham medidas de internação à adolescentes do sexo feminino e buscou identificar possíveis marcadores típicos da diferença de gênero que vinculassem, para aquele juízo, a necessidade de institucionalização daquela adolescente.

Em primeira análise, as figuras voltadas ao âmbito familiar foram identificadas em $36 \%$ das sentenças analisadas. ${ }^{33}$ Foram relatadas expressões vagas baseadas na "falta de controle" familiar perante àquela adolescente, afirmações de que a desagregação familiar é a causa da delinquência e até a indicação de que a delinquência reiterada poderia ser indicada pelo fato da adolescente possuir um "filho recém-nascido"34. Interessante notar que a figura da independência da adolescente da organização tradicional de uma família é capaz de justificar a institucionalização dessas jovens.

${ }^{32}$ MACHADO, E. B. L. A.; SILVA, W. F.; SILVA, A. S. G. Sentenças de medida socioeducativa de internação e gênero. O olhar dos magistrados em Pernambuco sobre as adolescentes em conflito com a lei. Revista da Faculdade de Direito UFPR. Curitiba. vol. 61, n. 2, 2016, p. 189 ss. Disponível em https://revistas.ufpr.br/direito/article/download/42294/29063.

${ }^{33}$ MACHADO, E. B. L. A.; SILVA, W. F.; SILVA, A. S. G., op. cit., p. 191 ss.

${ }^{34}$ MACHADO, E. B. L. A.; SILVA, W. F.; SILVA, A. S. G., op. cit., p. 192. 
Já em 93\% das sentenças analisadas, foram observadas figuras derivadas da reputação, demonstrando que a tutela estatal pretende extrapolar os limites objetivos circunscritos pelo tipo penal - que será equiparado na conduta do adolescente. Além do controle formal, do corpo, destas adolescentes, existe a inferência de um controle informal, subjetivo. Por óbvio, essas práticas encontram fundamento nas razões apresentadas no texto de SOUZA e FERRAZ, entretanto, se observadas diante da lente de aumento proporcionada pela investigação das relações de gênero, tais figuras ganham proporção. Isso porque avaliações, feitas pelo juízo e apresentadas no trabalho mencionado, como "arrependida" ou "desesperada" indicam uma imposição da localização do subjetivo da adolescente criminalizada. Essa localização tem sua raiz nos pontos de partida determinados pelo gênero, estereótipos da subjetividade feminina.

Outros dados, do mesmo estudo, podem salientar essa afirmação: em 12,5\% dos casos, a "tendência à prática do crime" foi elaborada por conta do relacionamento da adolescente com outros indivíduos criminalizados e $25 \%$ das sentenças levou em consideração o "histórico de vida" da adolescente para lhe impor a restrição de liberdade.

Dessa forma, o desvio dos formatos preconizados, identificado no discurso categórico dos marcadores típicos de gênero, é determinante para imposição das medidas socioeducativas de internação às adolescentes que entram em 
contato com a justiça juvenil. O gênero, enquanto dissimulação, é imiscuído no processo de criminalização destes indivíduos. Processo que, na justiça juvenil, tem seu fundamento nas razões expostas por SOUZA e FERRAZ.

A hipótese deste artigo ganha, neste ponto, um novo nível de profundidade: as relações de poder que foram identificadas no processo de criminalização primeiro - o da tipificação dos injustos -, ganham em potência. Deixam de ser figuras normativas supostas e são vinculadas materialmente àquele indivíduo através do Poder Judiciário, aqui exposto nos formatos da Justiça Juvenil.

É possível dizer, guardadas as ressalvas, que ser mulher/generificada enquanto mulher foi um dos principais fundamentos da aproximação destes indivíduos, mencionados no trabalho, com o sistema formal de controle. Resta observar como o sistema controle, aqui representado pelo Sistema Socioeducativo Brasileiro em suas medidas de internação, trata tais questões.

\section{A EXECUÇÃO DAS MEDIDAS SOCIOEDUCATIVAS DE INTERNAÇÃO: AS CONTRADIÇÕES DA RELAÇÃO DE PODER}

Segundo o relatório elaborado pelo CNJ, existe uma predominância de garotas, no sistema socioeducativo de 
internação, entre 15 e 17 anos (na data do ato infracional), não brancas, com rendas familiares indeterminadas, sendo mães solos suas responsáveis. Em grande parte, estavam entre 6o e o 9o ano antes de serem institucionalizadas - e segundo o relatório, em nenhuma das unidades visitadas foi identificada a continuidade dos estudos no exato ano no qual estavam inseridas. Em todo o Brasil, é destacado o percentual incrementado de adolescentes internadas por ato infracional análogo ao tráfico de drogas. ${ }^{35}$ Essa figura, é chamada por DINIZ de menina típica à unidade de internação. ${ }^{36}$

Diversas adolescentes, em todos os estados analisados, apresentam passagem anterior por outras instituições governamentais e/ou não governamentais, além de um índice de adolescentes que relata ter sofrido ameaças de morte, o que pode fundamentar ainda mais a indicativa de que o público selecionado pelo sistema de justiça juvenil é majoritariamente vulnerável socialmente, em suas comunidades e suas famílias. ${ }^{37}$

Das estruturas, Distrito Federal e São Paulo apresentam unidades bastante similares às prisões adultas, com altos e pesados muros e guaridas. Pernambuco e Pará possuem

35 BRASIL, op. cit., 2015, p. 21 ss.

${ }^{36}$ DINIZ, op. cit., 2017, p. 19.

${ }^{37}$ BRASIL, op. cit., 2015, p. 34 ss. 
unidades funcionando em áreas residenciais, por vezes superlotadas. ${ }^{38}$

Em relação às atividades pedagógicas e profissionalizantes, chama a atenção o fato de que no Distrito Federal, as atividades para os adolescentes do sexo masculino possuíam atividades voltadas à educação, enquanto a ala das adolescentes do sexo feminino, não. Em São Paulo, os cursos profissionalizantes são divididos em informática, culinária ou maquiagem/cabelo. Em Pernambuco também existem convênios para cursos de prática de cabelereiro e artesanato. ${ }^{39}$

A sexualidade e o gênero também são evidenciados no relatório: a expressiva maioria das unidades apresentadas no relatório não possuía espaço específico para mães e seus bebês, mesmo que a maternidade seja um direito, uma realidade, específica do sistema infracional feminino. Pernambuco e Distrito Federal, por exemplo, não possuem espaço específico para o exercício deste direito. São Paulo e Rio Grande do Sul possuem programas específicos para acompanhamento materno, ambos tendo apenas uma unidade servindo estes provimentos.

O relatório também traz uma importante passagem:

${ }^{38}$ Ibid., p. 62 s.

${ }^{39}$ BRASIL, op. cit., 2015, p. 70. 
As profissionais se referem às meninas do Pami como mais tranquilas e dóceis, talvez por terem-se tornado mães. Aqui é possível identificar como a "maternidade" é tida como um elemento transformador na vida dessas meninas. [...] Um fato que chamou atenção com relação a essas adolescentes da Pami é o de que elas não podiam ter qualquer tipo de relação com as demais adolescentes da unidade, com quem tinham contato apenas durante as aulas da escola oferecidas para todas. Isoladas em um prédio a parte dentro do mesmo terreno da unidade Chiquinha Gonzaga, elas acabam por compor uma comunidade própria na qual a solidariedade com as demais adolescentes dali de dentro era uma regra reforçada pelas educadoras de apoio. ${ }^{40}$

Dessa forma, é importante observar que esses aspectos de análise "gênero e sexualidade" demonstram a presença de tabus e gargalos. Exemplo disso é o fato de que quase nenhuma unidade previa a hipótese de visita íntima das adolescentes internadas, mesmo que muitas delas possuam companheiros e até filhos. Também é exemplificativo a ideia de que as adolescentes teriam sido "transformadas" por se tornarem mães no cenário específico da execução da medida socioeducativa: aqui a adolescente encontra a figura de gênero de forma concreta, torna-se mãe. Assim, seguindo a cartilha proposta pelas relações

${ }^{40}$ Ibid., 2015, p. 152. 
de gênero, não pode se misturar com as demais, deve, portanto, ficar isolada.

A sexualidade, as performances e a identidade de gênero são também controladas dentro dessas instituições. Exemplo disso é que o relacionamento homoafetivo entre adolescentes não é permitido - mesmo sendo uma prática recorrente. Em São Paulo, outro exemplo, é o fato da adolescente não ter a independência de raspar seus cabelos - muitas delas fazem isso para serem reconhecidas como "boys" 41 -, para isso, a adolescente precisa da anuência de seus familiares responsáveis. Parte dos funcionários entrevistado quando do relatório, relata preocupação com a readaptação das adolescentes se seu cabelo estiver curto.

Elaborado em 2017 por Débora Diniz, o relatório Meninas Fora da Lei carrega vários dados apresentados no relatório do CNJ, que são observados sob ótica pormenorizada, através de uma lupa. A visita à unidade socioeducativa de Santa Maria identifica o impacto das disfunções de gênero na execução das medidas das adolescentes internadas.

Importante dado é o percentual de garotas que "caíram" - foram abordadas e institucionalizadas - com seus maridos: $50 \%$ das adolescentes da unidade. Quatro do total de nove companheiros eram sujeitos mais velhos (entre 20 e 30

${ }^{41}$ BRASIL, op. cit., 2015, p. 179. 
anos) e cinco eram adolescentes também. Esse número corrobora com o os altos índices de internação de adolescentes por ato infracional análogo ao tráfico de drogas. Muitas das adolescentes internadas, como foi observado em COPELLO, se aproximam do sistema de Justiça Criminal por pressões típicas de gênero que são expressas no formato dos delitos cometidos.

Assim, é possível finalizar o ciclo proposto neste artigo: as adolescentes internadas são, durante a execução de suas medidas, atravessadas pelas relações de gênero, formal e informalmente. As figuras de gênero, enunciadas pelos magistrados da infância e juventude, são aqui estabelecidos como modelos a serem alcançados.

\section{CONSIDERAÇÕES FINAIS}

Este trabalho pretendeu observar, de forma sintética, três fases do processo de criminalização de adolescentes através da ótica das dissimulações de gênero presentes no sistema de justiça criminal, com enfoque bastante específico na justiça juvenil.

Importante destacar que, sob o enfoque da Justiça Juvenil, alguns paradigmas deverão nortear o debate: a proteção integral compartilhada e a prioridade absoluta da infância e 
juventude, dispositivos que pretendem inverter parte da lógica tutelar adotada por nossa cultura jurídica anterior à promulgação do complexo normativo que rege estas fases da vida humana na sociedade brasileira. Estes diplomas, a ex. o Estatuto da Criança e do Adolescente, a lei do SINASE, a Constituição Federal de 1988 e os pactos e convenções internacionais que tratam do tema, são considerados modernos e indicam a estruturação de um sistema que pretende, com objetivo máximo, a garantia do amplo desenvolvimento da criança e do adolescente.

Quando o assunto é a garantia de direitos da população de adolescentes - uma população que é, sabidamente, mais complexa - diversos desafios e gargalos são materializados na realidade brasileira, que afastam a concretização dos direitos, garantias e até da lógica estabelecida pelos dispositivos legais não mais a lógica menorista, mas a lógica garantista.

Desses desafios, a Justiça Juvenil é, materialmente, um dos mais graves e urgentes: um sistema antagônico àquele preconizado pelo ECA e pela lei do SINASE, servindo como um grande complexo de violação massiva de direitos de milhares de adolescentes. Essa afirmação é amparada pela recente decisão da 2. Turma do Supremo Tribunal Federal, que afirma o caráter violador de direitos do sistema socioeducativo brasileiro. Entretanto, nenhum adolescente é inserido no sistema socioeducativo sem antes a imposição de medida de internação. Aqui ganha destaque o problemático funcionamento da Justiça 
Juvenil durante o momento da imposição das medidas socioeducativas, como apresentado por SOUZA e FERRAZ.

Vigora uma coexistência entre o ideário menorista e o ideário garantista - disposto pela legislação - durante os processos de imposição das medidas. Nesse sentido, a lógica menorista, carregada nas decisões de magistrados Justiça Juvenil, legitima uma ampla capacidade estatal de institucionalização de adolescentes que não cumpram com a conformidade/expectativas médias. Essa institucionalização, sob essa ótica, é capaz de resguardar os direitos daquele adolescente e reintegrá-lo na "sociedade".

O gênero, como um parâmetro de conformidade principalmente de corpos -, serve como um importante marcador no momento da aproximação do adolescente com o sistema, como observado neste trabalho. Esse processo é gradativo e atua em três diferentes fases.

A primeira dessas fases, que foi neste trabalho tratada de forma mais ampla, pode ser identificada no trabalho de COPELLO: alguns formatos de injustos apresentam padrões de cometimento que são formatados pelas dissimulações de gênero, por vezes diretamente - ex. a mulher que sofre violência e mata o companheiro para se defender -, por vezes indiretamente - ex. o número incrementado de mulheres acusadas e penalizadas por tráfico de drogas, aproximadas deste mercado, muitas vezes, por conta da aproximação anterior de seus companheiros ou 
familiares. É possível afirmar, então, que existem criminalizações primárias das estruturações pautadas pelo gênero, mesmo que não sejam expressamente inseridas no tipo penal - que no âmbito de análise deste artigo, será considerado na analogia ao ato infracional praticado pelo adolescente.

Quando um indivíduo generificado enquanto mulher é criminalizado, inicia-se a segunda fase deste processo. Durante essa fase, são tidos como exemplares as figuras típicas de gênero, ou seja, os marcadores típicos da diferença entre àquela mulher criminalizada e os tipos ideais. Foram apresentados, neste trabalho, casos de adolescentes que foram aproximadas ao sistema de controle e encontraram, nesta segunda fase, a comparação aos tipos ideais, que ganham, na Justiça Juvenil, uma proporção potencializada: submetida à lógica menorista dos magistrados, a adolescente, que já é inserida no processo como desviante, é avaliada também perante os marcadores típicos do gênero. Identificado o desvio, é legitimada a institucionalização. Em resumo, o gênero, no caso das adolescentes, é um intensificador da criminalização, quando deveria, na verdade, garantir uma tratativa menos invasiva.

Diante do exposto, a hipótese inicial pode ser alcançada e demonstrada: os marcadores típicos de gênero, observáveis quando no cometimento do delito, servem como parâmetros para criminalização secundária de mulheres. Esse 
processo é ainda mais extensivo na Justiça Juvenil, garantido pela lógica menorista de parte dos magistrados.

Uma vez determinada a medida socioeducativa de internação, as adolescentes são enviadas às unidades educacionais. Se essas meninas foram, primeiramente, criminalizadas por conta dos estigmas de gênero, o sistema trabalha, segundo a lógica garantista da legislação, para reduzir esses estigmas? A resposta, como demonstrado, é não: o sistema socioeducativo, pelo que foi identificado no material estudado, intensifica figuras e hierarquias de gênero. A execução das medidas de internação é atravessada por diversas imposições de gênero, determinando a "ressocialização" daquela adolescente às figuras tradicionais das performances tradicionais. $\mathrm{O}$ exemplo mais pitoresco dessa característica é o da separação das adolescentes que se tornaram mães já inseridas no sistema das outras adolescentes institucionalizadas. Isso se dá para "garantir" o novo eixo adotado por aquela adolescente exercendo a maternidade.

Fica, assim, evidenciada a contradição exposta na hipótese primeira deste trabalho: para garantir a "proteção integral e com absoluta prioridade" de nossa comunidade de adolescentes, é importante destacar a necessidade específica das adolescentes generificadas enquanto mulheres. Isso porque as relações de gênero atravessam e dissimulam os estabelecimentos de poder em todas esferas e fases da vida. Essa afirmação é 
bastante observada no âmbito da Justiça Juvenil: essas relações, hierarquias e dissimulações estruturadas pelo gênero criminalizam e institucionalizam essas meninas e, paradoxalmente, são incentivados e ensinados às adolescentes. Cabe a comunidade especializada observar com atenção e cuidado a elaboração dessas estruturas e sob quais formatos elas acabam se materializando. A proteção integral, portanto, só será alcançada quando tratadas e observadas todas estruturas que garantem as hierarquias de poder fundamentais para a desigualdade: a classe, a raça e o gênero.

\section{REFERÊNCIAS}

BRASIL. Dos espaços aos direitos. A realidade da ressocialização na aplicação das medidas socioeducativas de internação das adolescentes do sexo feminino em conflito com a lei nas cinco regiões. Coord. MELLO, M. M. P. Pesquisadores BASTOS, C. A. V, et al. Brasília: Conselho Nacional de Justiça, 2015.

COPELLO, P. L. Mujeres em el abismo: delinquência feminina em contextos de violência o exclusión. Revista Electrónica de Ciência Penal y Criminologia. vol. 21. 2019. Disponível em http://criminet.ugr.es/recpc/. Último acesso em set. de 2020. 
DINIZ, D. Meninas fora da lei: a medida socioeducativa de internação no Distrito Federal. Brasília: LetrasLivres, 2017.

DINIZ, D.; GUMIERI, S. Violência de gênero no Brasil: ambiguidades da política criminal. In: GOMES, M. G. M.; FALAVIGNO, C. F.; MATA; J. [Orgs.]. Questões de gênero: uma abordagem sob a ótica das ciências criminais. Belo Horizonte: D’Plácido, 2018. p. 195-208.

LE BLAC, M. On the future of the individual longitudinal agecrime curve. Crim Behav Ment Health. vol. 30. 2020. p. 183-195. Disponível em https://doi.org/10.1002/cbm.2159.

LIMA, F. S; VERONESE, J. R. P. Direitos da criança e do adolescente. A necessária efetivação dos direitos fundamentais. Coleção pensando o direito no século XXI. Vol. V. Florianópolis: FUNJAB, 2012, p. 51-60.

MACHADO, E. B. L. A.; SILVA, W. F.; SILVA, A. S. G. Sentenças de medida socioeducativa de internação e gênero. $O$ olhar dos magistrados em Pernambuco sobre as adolescentes em conflito com a lei. Revista da Faculdade de Direito UFPR. Curitiba. vol. 61, n. 2, $2016 . \quad$ Disponível em https://revistas.ufpr.br/direito/article/download/42294/29063. 
PISCITELLI, A. Recriando a (categoria) mulher? In: ALGRANTI, L. (Org.). A prática feminista e o conceito de gênero. Textos Didáticos, n. 48. Campinas: IFCH/Unicamp, 2002, p. 7-42.

SAFFIOTI, H. I. B. Gênero, patriarcado, violência. 2. ed. São Paulo: Graphium, 2011.

SEGATO, L. R. Feminicidio y femicidio: conceptualización y apropriación. In: JIMÉNEZ, P.; RONDEROZ, K (Ed.). Feminicidio: um fenómeno global de Lima a Madrid. Bruxelas: Heinrich Böll Stiftung, 2010. p. 5 ss.

SOUZA, F. S. V.; FERRAZ, H. G. A responsabilidade do judiciário brasileiro no encarceramento em massa juvenil: um estudo de caso do HC 346.380-SP, STJ. Revista Brasileira de Ciências Criminais. vol. 129. ano 25. p. 257-284. São Paulo: Ed. RT, março 2017.

BRASIL. Supremo Tribunal Federal (2. Turma). Habeas Corpus Coletivo 143988/ES. Habeas Corpus coletivo. Cumprimento de medidas socioeducativas de internação. Impetração voltada a corrigir alegada superlotação em unidades [...]. Relator Min. Edson Fachin. 24 de agosto de 2020. 